\title{
Height and blood chemistry in adults with a history of developmental arsenic poisoning from contaminated milk powder
}

\section{Citation}

Yorifuji, Takashi, Kenichi Matsuoka, and Philippe Grandjean. 2017. "Height and Blood Chemistry in Adults with a History of Developmental Arsenic Poisoning from Contaminated Milk Powder." Environmental Research 155 (May): 86-91. doi:10.1016/j.envres.2017.02.002.

\section{Published Version}

10.1016/j.envres.2017.02.002

\section{Permanent link}

http://nrs.harvard.edu/urn-3:HUL.InstRepos:37221724

\section{Terms of Use}

This article was downloaded from Harvard University's DASH repository, and is made available under the terms and conditions applicable to Open Access Policy Articles, as set forth at http:// nrs.harvard.edu/urn-3:HUL.InstRepos:dash.current.terms-of-use\#OAP

\section{Share Your Story}

The Harvard community has made this article openly available.

Please share how this access benefits you. Submit a story.

\section{Accessibility}


Height and Blood Chemistry in Adults with a History of Developmental Arsenic Poisoning from Contaminated Milk Powder

Takashi Yorifuji ${ }^{\mathrm{a}}$, Kenichi Matsuoka ${ }^{\mathrm{b}}$, Philippe Grandjean ${ }^{\mathrm{c}, \mathrm{d}}$

${ }^{a}$ Department of Human Ecology, Graduate School of Environmental and Life Science,

Okayama University, Okayama, 700-8530, Japan

${ }^{\mathrm{b}}$ Mizushima Kyodo Hospital, Kurashiki, Okayama, 712-8567, Japan

${ }^{c}$ Department of Environmental Health, Harvard T.H. Chan School of Public Health, Boston, MA 02215, USA

${ }^{\mathrm{d}}$ Department of Environmental Medicine, University of Southern Denmark, DK-5000, Odense, Denmark

\section{Corresponding author:}

Takashi Yorifuji, MD

Department of Human Ecology, Graduate School of Environmental and Life Science,

Okayama University, 3-1-1 Tsushima-naka, Kita-ku, Okayama 700-8530, Japan

Tel: +81-86-251-8925; E-mail: yorichan@md.okayama-u.ac.jp 


\section{Abstract}

Background: Arsenic poisoning interferes with bone metabolism in laboratory animal studies, and human studies suggest lowered bone mass density at elevated exposures. As the long-term consequences of developmental arsenic toxicity are poorly known, we carried out a clinical pilot study of survivors of the mass arsenic poisoning of bottle-fed infants in Japan in 1955.

Objectives: The purpose was to evaluate the association between developmental arsenic exposure and physical stature and routine blood chemistry reflecting major organ functions more than 50 years later.

Methods: The study sample consisted of 50 individuals recruited at two hospitals in Okayama Prefecture, Japan: 27 known poisoning victims (14 men and 13 women), and 23 non-exposed local controls of similar age (10 men, 13 women). We collected information from physical examinations that included routine blood counts and blood biochemistry. Results: The average height of the exposed group was $6.5 \mathrm{~cm}$ below that of the unexposed group ( $p=0.02$ ), while the latter was in accordance with national data for both sexes. In addition, the exposed participants had a higher mean (SD) serum concentration of alkaline phosphatase (ALP) of 233 (63) U/L than the unexposed participants (191 (44) U/L) ( $p=$ 0.01). No other statistically significant difference was observed, and liver enzymes were within normal ranges.

Conclusions: Adults who had suffered arsenic poisoning during infancy showed decreased height and elevated ALP that suggests abnormalities in bone metabolism possibly induced by arsenic incorporated in the bone matrix. 
Keywords: alkaline phosphatase; arsenic poisoning; bone metabolism; height; infancy

Funding Sources: This work was supported by a Grant-in-Aid for Young Scientists (B) (No. 23790662) from the Ministry of Education, Culture, Sports, Science and Technology, Japan.

Declaration of Interest Statement: The authors declare that they have no conflicts of interest. 


\section{Introduction}

Chronic exposure arsenic via inhalation or drinking water ingestion is linked to cancer of the lung, skin, kidney, and urinary bladder (Straif et al. 2009) and an increased risk of a variety of other non-communicable diseases (National Research Council 1999). Apart from neurotoxicity, evidence on long-term effects of developmental toxicity of arsenic is limited (Vahter 2008), but possible adverse effects on birth outcomes include low birth weight (Bloom et al. 2014; Gilbert-Diamond et al. 2016; Kile et al. 2016; Rahman et al. 2009). Further, a prospective cohort study from Bangladesh suggests an inverse association between early-life arsenic exposure from contaminated drinking water and children's growth during infancy (Gardner et al. 2013; Saha et al. 2012). Growth inhibition due to arsenic exposure has been supported by laboratory animal studies that show decreased body length and femur length (Hu et al. 2012), as well as decreased bone mass density (Wu et al. 2014). A cross-sectional study of adult males reported an inverse association between environmental arsenic exposure and bone mass density (Akbal et al. 2014). In vitro studies have reported arsenic-induced decreased mineralization of osteoblasts in primary cell cultures (Hu et al. 2012), decreased osteoblast differentiation (Wu et al. 2014), and increased differentiation of preosteoclasts (Szymczyk et al. 2006). Arsenate likely substitutes phosphate in the skeletal apatite crystals (Lindgren et al. 1982), and arsenic exposure causes a decreased expression of alkaline phosphatase (ALP) (Hu et al. 2012), an enzyme that hydrolyzes pyrophosphate and provides inorganic phosphate needed for bone mineralization (Millan 2013).

As further evidence is needed regarding the long-term consequences of developmental arsenic toxicity, we carried out a pilot study of surviving patients who were poisoned by arsenic in infancy (Yorifuji et al. 2016). The mass arsenic poisoning of bottle-fed infants happened in the western part of Japan during the summer of 1955 . The cause was contaminated milk powder, and the estimated arsenic concentration in the reconstituted milk 
was about 4-7 mg/L (Dakeishi et al. 2006; Hamamoto 1957). The exposures lasted for about four months from the change in formulation of the milk powder in April 1955 until the recall on August 24, 1955 (Hamamoto 1957). Approximately 13,000 children were affected and manifested skin pigmentation, diarrhea, and fever; more than 100 died from acute poisoning (Hamamoto 1957). Unfortunately, long-term follow-up studies of the victims have not been carried out, and the absence accessible registries hampers any follow-up studies (Yorifuji et al. 2011).

We recently conducted a pilot study of a small group of poisoned victims and nonexposed controls of similar age; the primary focus was on the long-term effects of developmental arsenic exposure on neurological outcomes more than 50 years later (Yorifuji et al. 2016). We found that exposed participants had more unfavorable neuropsychological outcomes than the unexposed controls, which is consistent with previous studies suggesting developmental neurotoxicity of arsenic exposure (Smith and Steinmaus 2009; Tolins et al. 2014; Vahter 2008). We are now reporting the results of the general physical examination and routine blood chemistry, where we explored a variety of parameters that may reflect organ dysfunctions, including bone metabolism. This unique incident of arsenic exposure may provide useful information to elucidate whether developmental arsenic exposure results in adverse effects that persist through mature ages.

\section{Materials and Methods}

\subsection{Study setting}

During the period from April 2012 to February 2013, we conducted a retrospective cohort study of participants at two hospitals (Okayama Kyoritsu Hospital and Mizushima Kyodo Hospital) in Okayama Prefecture, Japan. We selected Okayama Prefecture because the Prefecture was the most severely affected area in the country (Hamamoto 1957). We 
collected information on physical status and blood examination in connection with the regular health examinations offered to registered victims and conducted at the two participating hospitals. We also collected a urine specimen for arsenic analysis. The unexposed subjects were examined by the same methods; blood and urine samples were coded, but blinding of the clinical examiner was not possible. Demographic characteristics including past medical history were obtained from a questionnaire, but arsenic exposure levels in infancy, duration of breastfeeding, and detailed residential history were unavailable. The study setting and methods are described in further detail in our previous report (Yorifuji et al. 2016). The study was approved by the Institutional Review Boards of Okayama University (protocol No. 487) and at each hospital.

\subsection{Study participants}

We included 50 participants who provided written, informed consent for participation in the study: 27 among known poisoned victims (14 men and 13 women) in Okayama Prefecture and 23 local, non-exposed controls (10 men and 13 women). Among those invited, three exposed $(10.0 \%)$ and three non-exposed individuals $(11.5 \%)$ refused to participate in the study.

The exposed participants were identified in part from the list of victims known to the Hikari Association to receive free regular health examinations at the two hospitals $(n=15)$. The Hikari Association is a public-interest foundation dedicated to providing permanent relief for the victims of the contaminated milk powder. It supports victims through various efforts such as benefits, including living allowance, and regular health examinations for those who have disabilities or a relevant medical diagnosis. According to the Hikari Association, it supports regular health examinations for victims with disorders specific to arsenic poisoning, such as skin lesions, mental disorder, or intellectual disability. Among the 15 participants 
identified through the Association, 12 received benefits for their disorders, while three participants did not, because they did not suffer from qualifying disorders. The list of exposed participants was supplemented by a list of victims who did not receive regular health examinations offered by the Hikari Association but who could be reached through the two local hospitals $(n=12)$; the hospitals offered health care to these victims regardless of their current health status and certification.

We also recruited 23 non-exposed controls from medical staff at the two hospitals, including clerks, nurses, and laboratory technicians, at ages similar to the exposed participants. None of them had been exposed to the contaminated milk powder during infancy, but information whether they were breastfed or formula-fed with other milk powder could not be obtained.

\subsection{Medical examination}

The regular health examinations recorded physical status (height, weight, blood pressure at rest, visual acuity, hearing acuity), blood analyses (complete blood count and biochemical blood tests), urine analysis (urine protein, blood, and sugar), chest X-ray, and electrocardiogram. The same standardized procedures were used at the two participating hospitals. In the present study, we selected physical status including height, weight, and blood pressure at rest as well as blood counts and biochemistry as the parameters most relevant in regard to childhood arsenic exposure. Neurobehavioral outcomes were analyzed in a previous report (Yorifuji et al. 2016).

\subsection{Urine arsenic analysis}

During the health examinations, we collected $10 \mathrm{~mL}$ spot urine samples for immediate freezing at $-80^{\circ} \mathrm{C}$. The frozen samples were couriered to the National Institute of 
Environmental Health, USA for arsenic analysis. The samples were acidified with nitric acid before determination of arsenic species by atomic absorption spectrophotometry (ref).

\subsection{Statistical analyses}

We compared demographic characteristics between exposed and unexposed participants to identify possible confounders. We then compared the clinical results on physical status, blood analyses, and urine arsenic analysis between the two groups. Because alcohol status may affect blood biochemistry, we repeated the analyses after exclusion of participants who reported drinking alcohol every day. In addition, as arsenic is reported to increase risks of liver disease, diabetes mellitus, and neurocognitive dysfunctions (Das et al. 2012; Islam et al. 2011; Maull et al. 2012; Yorifuji et al. 2016), we excluded those diagnosed with these diseases before repeating the analyses. We also carried out the same analyses after stratification by sex.

In our previous study, we observed that exposed participants had more unfavorable neuropsychological outcomes than the unexposed participants, in particular for Design memory subtest from Wide Range Assessment of Memory and Learning 2 and Grooved pegboard test (both dominant and non-dominant hands) (Yorifuji et al. 2016). As an exploratory analysis not included in the original protocol, we examined the correlation of these tests with other clinical outcome parameters significantly associated with exposure status in order to ascertain the possible phenotypic pattern of sequelae from arsenic poisoning during infancy.

We used Chi-square tests for binary outcomes and t-tests for continuous outcomes. PASW Statistics software (SPSS Japan Inc., version 18.0J) was used for the analyses. We report two-sided $p$ values, and those less than 0.05 were considered statistically significant. 


\section{Results}

Demographic characteristics by exposure status are shown in Table 1. While age and sex distributions were similar, the unexposed participants were more likely to consume alcohol, have higher education, and to be employed. Although not significant, the exposed participants were more likely to have been diagnosed with neuropsychiatric disorders (e.g., depression and epilepsy). Concentrations of arsenic species in urine were not significantly different between the groups (Table 2).

Table 3 shows physical status of the participants. The exposed participants had lower height (mean, $155.2 \mathrm{~cm})$ compared to the unexposed participants (mean, $161.7 \mathrm{~cm})(p=$ 0.01). According to the "National Health and Nutrition Survey" conducted in 2012 by the Japanese Ministry of Health, Labor, and Welfare, the average height at 50-59 years of age was $168.6 \mathrm{~cm}(\mathrm{SD}, 5.7)$ for men and $156.1 \mathrm{~cm}(\mathrm{SD}, 5.3)$ for women. The average height in unexposed male controls in the present study was $168.6 \mathrm{~cm}(\mathrm{SD}, 7.0)$ and in females 156.3 $\mathrm{cm}(\mathrm{SD}, 5.9)$, both in close agreement with the national average values.

Blood chemistry results are shown in Table 4 . The exposed participants had higher ALP concentrations than the unexposed participants, but other findings were not significantly different between the groups. When separated by sex, similar tendencies for ALP were observed (Table 5). Even after exclusion of participants with daily alcohol usage $(n=7)$ or with diagnosis of liver disease $(n=11)$, diabetes mellitus $(n=8)$, or neuropsychiatric disorders $(n=8)$, the findings did not change, i.e., the exposed participants had higher ALP values when compared to the unexposed participants, although all results were within the reference interval used in Japan. The four participants with a result in the high-normal range (300-350 $\mathrm{U} / \mathrm{L})$ all belonged to the exposed group.

In exploratory analyses, we calculated correlation coefficients for height and ALP regarding the main neuropsychological outcomes, i.e., Design memory and Grooved 
pegboard scores. In exposed subjects, the former correlated significantly with subject height $(\mathrm{r}=0.41, p=0.04)$ and ALP $(\mathrm{r}=-0.47, p=0.02)$. Correlation coefficients with pegboard scores for the dominant hand were $-0.48(p=0.01)$ for height and $0.37(p=0.09)$ for ALP. Other neurobehavioral tests showed similar, though weaker, associations. All of these tendencies suggested increasing deficits at lower height and higher ALP concentrations, while similar tendencies were not found among unexposed participants (data not shown).

\section{Discussion}

The present study is unique, as it refers to current health in subjects who, as infants more than 50 years ago, were exposed to arsenic poisoning from contaminated milk powder (Yorifuji et al. 2016). This episode affected thousands of victims, most of whom were infants who received the exposure from bottle-feeding. While neurological sequelae were reported in exposed subjects at adolescence, very limited follow-up has been accomplished (Dakeishi et al. 2006). For the first time, the present study reports the physical status and blood examinations of surviving victims at adult age.

The average height of the exposed group was $6.5 \mathrm{~cm}$ below that of the unexposed group. Although a small part of this substantial difference could perhaps be attributable to body posture, the standardized assessment of height in standing position suggests that the observed difference is real. Height may be inversely associated with longevity (He et al. 2014), but a differential mortality before age 60 years would be unlikely to generate a difference in height as large as the one observed. A previous study from this mass arsenic poisoning already reported lower height among exposed victims at adolescence, although details were not provided (Uehata et al. 1977). In addition, a prospective cohort study from Bangladesh suggested an inverse association between early-life exposure to arsenic and height at infancy (Gardner et al. 2013; Saha et al. 2012). 
A possible explanation for decreased height may be related to the similarity between arsenate and phosphate, thus leading to replacement of phosphorus by arsenic and accumulation of the latter in bone tissue (Hosain et al. 1980; Lindgren et al. 1982). Because phosphate is crucial for bone growth and mineralization (Penido and Alon 2012), lack of phosphate due to substitution by arsenic may have led to shorter height among the exposed participants. Indeed, arsenic may affect bone metabolism, as shown in experimental studies (Aybar Odstrcil et al. 2010; Hu et al. 2012; Szymczyk et al. 2006; Wu et al. 2014), and arsenic exposure inhibits endochondral ossification and osteoblast differentiation (Aybar Odstrcil et al. 2010; Wu et al. 2014). In humans, chronic exposure is associated with diminished bone mass density in adult males (Akbal et al. 2014). Of possible relevance, an inverse association has been reported between arsenic exposure and the plasma concentration of insulin-like growth factor 1 in preschool children (Ahmed et al. 2013). Adverse effects of environmental exposure to metals, such as lead and cadmium, on children's growth and insulin-like growth factor 1, support the notion that developmental exposures can affect height achieved at adult age (Afeiche et al. 2012; Burns et al. 2012; Fleisch et al. 2013; Gardner et al. 2013).

In addition, we observed that the average value of ALP was considerably higher among the exposed group, compared to the unexposed group. ALP refers to a group of phosphomonoesterases that hydrolyze phosphate esters; most of the ALP in serum originates from either liver or bone, and higher serum-ALP concentrations occur in diseases affecting these organs. The bone-specific ALP is formed in osteoclasts and is thought to be involved in the calcification of the bone matrix, with elevated serum concentrations reflecting increased bone metabolism and accelerated bone formation (Van Hoof and De Broe 1994; Vroon and Israili 1990). Exclusion of subjects with liver disease or daily alcohol use did not materially 
change the difference in ALP between the two study groups, thus suggesting that changes in liver functions did not affect the results.

Studies conducted in communities with high water-arsenic concentrations have demonstrated positive associations of arsenic exposure with higher levels of aminotransferases as well as ALP among adult participants currently exposed to arsenic, thus suggesting a possible impact of liver dysfunction (Das et al. 2012; Islam et al. 2011). However, our study did not reveal any differences between the two groups of subjects in aminotransferases or bilirubin, which were generally within the reference intervals, and the elevated ALP could therefore not be attributed to liver dysfunction. Rather, the difference in ALP may be related to alterations in bone metabolism (Penido and Alon 2012).

Experimental studies suggest that arsenic causes a decreased expression of ALP (Hu et al. 2012), which is opposite in direction to the results of the present study. The exposed subjects had a history of arsenic poisoning in infancy but not of any subsequent or current arsenic exposure (Table 2), and our findings therefore reflect a long-term response, not an effect of a recent or ongoing exposure. The elevated ALP could potentially be due to accumulated arsenic in bone tissue and could reflect compensatory changes related to abnormal bone metabolism induced by the presence of arsenic. Further clarification of these issues will require more extensive studies that compare larger numbers of subjects in regard to current and past exposures to arsenic, preferably with characterization of ALP isotypes.

In contrast, we did not observe significant differences in other blood chemistry indicators, including glucose metabolism, neither before nor after exclusion of participants with diabetes mellitus. While chronic arsenic exposure is associated with an increased diabetes incidence (Maull et al. 2012), this disease is apparently less likely to be triggered by early-life exposure to arsenic. On the other hand, this conclusion must remain tentative at this point, as the population examined represents survivors that may not reveal the full range of 
adverse effects induced by arsenic poisoning in infancy (Dakeishi et al. 2006; Yorifuji et al. 2011).

In our exploratory analyses, we observed that height and ALP were correlated with neuropsychological outcomes in the exposed subjects. Unfavorable neuropsychological outcomes in subjects poisoned by arsenic in infancy likely reflect permanent changes in brain functions (Yorifuji et al. 2016). While changes in height or ALP are unlikely to be mechanistically associated with brain development, the correlations support the notion that neuropsychological deficits coexist with decreased height and abnormal ALP concentrations as permanent sequelae of arsenic exposure during infancy.

There are several limitations in the present study. First, the number of subjects examined is small because we recruited only surviving victims living in Okayama Prefecture. Still, the study sample represents the patient population that could be reasonably identified in the local community of Okayama. Apart from the Hikari Association's register of victims receiving compensation, no general listing of victims is available today. Our approach to inviting Morinaga milk poisoning victims undergoing routine physical examinations therefore represents a feasible and reproducible means of selecting subjects with a history of severe arsenic exposure during infancy. However, many victims were probably not known to the hospitals, especially milder cases. An additional weakness is that we lack information on the total dose of arsenic among the exposed participants. The arsenic concentration differed by lot number of the milk powder (Dakeishi et al. 2006), and the duration of bottle-feeding is poorly documented in available records, thus making any dose calculation unrealistic. The control group was a convenience comparison group matched for age and with similar sex distribution, and potential confounders were examined only in stratified analyses due to the exploratory nature of the study. However, the results of this study did not change materially even after the exclusion of participants with daily alcohol intake or relevant diagnoses. Also, 
as the exposed subjects examined were provided with ongoing health care support from the Hikari Association, it is possible that any blood chemistry abnormalities in the victims were alleviated by past or current medical treatment, thereby minimizing differences from the unexposed subjects. Among possible confounders, developmental exposures to other toxicants, such as lead (Afeiche et al. 2012), could have affected attained height, but such exposures could not be quantified, although they would seem to be of little relevance in comparison with arsenic poisoning.

\section{Conclusions}

The present study showed that adults who suffered arsenic poisoning during infancy had lower height and higher serum-ALP concentrations compared to non-exposed subjects of the same age. In concert with findings in experimental studies, our results suggest that developmental arsenic exposure during infancy can result in skeletal abnormalities, as reflected by decreased height at adult age. As high arsenic concentrations may prevail in the bone tissue, the increased serum-ALP concentrations likely reflect the presence of altered bone metabolism; that may differ from the short-term effects.

\section{Acknowledgments:}

We appreciate valuable support from Shoko Namio, Masanori Chikama, Eiko Hayashi, Miyoko Matsuzaki (Okayama Kyoritsu Hospital), Kazuhiko Satomi, Hitoshi Ohta, Toshiko Murakami, Sachiko Yamamoto (Mizushima Kyodo Hospital), Makoto Imura (Imura Clinic), Hiroyuki Doi, Toshihide Tsuda, Akiko Tokinobu, Saori Irie (Okayama University), Tsuguhiko Kato (National Center for Child Health and Development) and staff at both hospitals. We also acknowledge ... at the National Toxicology Program of the National 
Institute for Environmental Health Sciences (NIH) for carrying out the urine analyses for arsenic species.

\section{References}

Afeiche M, Peterson KE, Sanchez BN, Schnaas L, Cantonwine D, Ettinger AS, et al. 2012. Windows of lead exposure sensitivity, attained height, and body mass index at 48 months. $\mathrm{J}$ Pediatr 160:1044-1049.

Ahmed S, Rekha RS, Ahsan KB, Doi M, Grander M, Roy AK, et al. 2013. Arsenic exposure affects plasma insulin-like growth factor 1 (igf-1) in children in rural bangladesh. PLoS One 8:e81530.

Akbal A, Yilmaz H, Tutkun E. 2014. Arsenic exposure associated with decreased bone mineralization in male. Aging Male 17:256-258.

Aybar Odstrcil AC, Carino SN, Ricci JC, Mandalunis PM. 2010. Effect of arsenic in endochondral ossification of experimental animals. Exp Toxicol Pathol 62:243-249. Bloom MS, Surdu S, Neamtiu IA, Gurzau ES. 2014. Maternal arsenic exposure and birth outcomes: A comprehensive review of the epidemiologic literature focused on drinking water. Int J Hyg Environ Health 217:709-719.

Burns JS, Williams PL, Sergeyev O, Korrick SA, Lee MM, Revich B, et al. 2012. Serum concentrations of organochlorine pesticides and growth among russian boys. Environ Health Perspect 120:303-308.

Dakeishi M, Murata K, Grandjean P. 2006. Long-term consequences of arsenic poisoning during infancy due to contaminated milk powder. Environ Health 5:31.

Das N, Paul S, Chatterjee D, Banerjee N, Majumder NS, Sarma N, et al. 2012. Arsenic exposure through drinking water increases the risk of liver and cardiovascular diseases in the population of west bengal, india. BMC Public Health 12:639. 
Fleisch AF, Burns JS, Williams PL, Lee MM, Sergeyev O, Korrick SA, et al. 2013. Blood lead levels and serum insulin-like growth factor 1 concentrations in peripubertal boys. Environ Health Perspect 121:854-858.

Gardner RM, Kippler M, Tofail F, Bottai M, Hamadani J, Grander M, et al. 2013.

Environmental exposure to metals and children's growth to age 5 years: A prospective cohort study. Am J Epidemiol 177:1356-1367.

Gilbert-Diamond D, Emond JA, Baker ER, Korrick SA, Karagas MR. 2016. Relation between arsenic exposure and birth outcomes in a cohort of mothers and their newborns from new hampshire. Environ Health Perspect.

Hamamoto E. 1957. [report of arsenic poisoning incident due to powdered milk in okayama prefecture (in japanese)]. Okayama:Department of health, Okayama prefecture, Okayama. He Q, Morris BJ, Grove JS, Petrovitch H, Ross W, Masaki KH, et al. 2014. Shorter men live longer: Association of height with longevity and foxo3 genotype in american men of japanese ancestry. PLoS One 9:e94385.

Hosain P, Spencer RP, Hosain F, Sripada PK. 1980. Arsenic for phosphorus substitution: Analogs of bone-seeking agents which bind technetium-99m. Int J Nucl Med Biol 7:51-53. Hu YC, Cheng HL, Hsieh BS, Huang LW, Huang TC, Chang KL. 2012. Arsenic trioxide affects bone remodeling by effects on osteoblast differentiation and function. Bone 50:14061415.

Islam K, Haque A, Karim R, Fajol A, Hossain E, Salam KA, et al. 2011. Dose-response relationship between arsenic exposure and the serum enzymes for liver function tests in the individuals exposed to arsenic: A cross sectional study in bangladesh. Environ Health 10:64. Kile ML, Cardenas A, Rodrigues E, Mazumdar M, Dobson C, Golam M, et al. 2016. Estimating effects of arsenic exposure during pregnancy on perinatal outcomes in a bangladeshi cohort. Epidemiology 27:173-181. 
Lindgren A, Vahter M, Dencker L. 1982. Autoradiographic studies on the distribution of arsenic in mice and hamsters administered 74as-arsenite or -arsenate. Acta Pharmacol Toxicol (Copenh) 51:253-265.

Maull EA, Ahsan H, Edwards J, Longnecker MP, Navas-Acien A, Pi J, et al. 2012.

Evaluation of the association between arsenic and diabetes: A national toxicology program workshop review. Environ Health Perspect 120:1658-1670.

Millan JL. 2013. The role of phosphatases in the initiation of skeletal mineralization. Calcif Tissue Int 93:299-306.

National Research Council SoAiDW. 1999. Arsenic in drinking water. Washington, D.C.:National Academy Press.

Penido MG, Alon US. 2012. Phosphate homeostasis and its role in bone health. Pediatr Nephrol 27:2039-2048.

Rahman A, Vahter M, Smith AH, Nermell B, Yunus M, El Arifeen S, et al. 2009. Arsenic exposure during pregnancy and size at birth: A prospective cohort study in bangladesh. Am J Epidemiol 169:304-312.

Saha KK, Engstrom A, Hamadani JD, Tofail F, Rasmussen KM, Vahter M. 2012. Pre- and postnatal arsenic exposure and body size to 2 years of age: A cohort study in rural bangladesh. Environ Health Perspect 120:1208-1214.

Smith AH, Steinmaus CM. 2009. Health effects of arsenic and chromium in drinking water: Recent human findings. Annu Rev Public Health 30:107-122.

Straif K, Benbrahim-Tallaa L, Baan R, Grosse Y, Secretan B, El Ghissassi F, et al. 2009. A review of human carcinogens--part c: Metals, arsenic, dusts, and fibres. Lancet Oncol 10:453454.

Szymczyk KH, Kerr BA, Freeman TA, Adams CS, Steinbeck MJ. 2006. Involvement of hydrogen peroxide in the differentiation and apoptosis of preosteoclastic cells exposed to arsenite. Biochem Pharmacol 72:761-769. 
Tolins M, Ruchirawat M, Landrigan P. 2014. The developmental neurotoxicity of arsenic: Cognitive and behavioral consequences of early life exposure. Annals of global health $80: 303-314$.

Uehata T, Sasagawa N, Mizuochi O, Shigemi K, Matsuoka K, Yuhara A. 1977. Health examination of morinaga milk poisoning victims (in japanese). In: [morinaga milk poisoning and miniren iryo]. Okayama, Japan:Okayamaken Minshuiryokikanrengo, 531-555.

Vahter M. 2008. Health effects of early life exposure to arsenic. Basic Clin Pharmacol Toxicol 102:204-211.

Van Hoof VO, De Broe ME. 1994. Interpretation and clinical significance of alkaline phosphatase isoenzyme patterns. Crit Rev Clin Lab Sci 31:197-293.

Vroon DH, Israili Z. 1990. Alkaline phosphatase and gamma glutamyltransferase. In: Clinical methods: The history, physical, and laboratory examinations, Part 3rd (Walker HK, Hall WD, Hurst JW, eds). Boston.

Wu CT, Lu TY, Chan DC, Tsai KS, Yang RS, Liu SH. 2014. Effects of arsenic on osteoblast differentiation in vitro and on bone mineral density and microstructure in rats. Environ Health Perspect 122:559-565.

Yorifuji T, Tsuda T, Doi H, Grandjean P. 2011. Cancer excess after arsenic exposure from contaminated milk powder. Environ Health Prev Med 16:164-170.

Yorifuji T, Kato T, Ohta H, Bellinger DC, Matsuoka K, Grandjean P. 2016. Neurological and neuropsychological functions in adults with a history of developmental arsenic poisoning from contaminated milk powder. Neurotoxicol Teratol 53:75-80. 
Table 1. Demographic characteristics of the participants separated by exposure status.

\begin{tabular}{|c|c|c|c|}
\hline & $\begin{array}{l}\text { Exposed } \\
\qquad n=27\end{array}$ & $\begin{array}{l}\text { Unexposed } \\
\qquad \mathrm{n}=23\end{array}$ & $p$ value \\
\hline Age; y, mean (SD) & $57.7(0.4)$ & $57.9(1.1)$ & 0.32 \\
\hline \multicolumn{4}{|l|}{ Sex; n (\%) } \\
\hline Male & $14(51.9)$ & $10(43.5)$ & 0.58 \\
\hline Female & $13(48.1)$ & $13(56.5)$ & \\
\hline \multicolumn{4}{|l|}{ Hospital; n (\%) } \\
\hline Okayama Kyoritsu Hospital & $17(63)$ & $10(43.5)$ & 0.26 \\
\hline Mizushima Kyodo Hospital & $10(37)$ & $13(56.5)$ & \\
\hline \multicolumn{4}{|l|}{ Smoking status; n (\%) } \\
\hline Non-smoker & $19(70.4)$ & $15(65.2)$ & 0.11 \\
\hline Smoker & $5(18.5)$ & $1(4.3)$ & \\
\hline Ex-smoker & $3(11.1)$ & $7(30.4)$ & \\
\hline \multicolumn{4}{|l|}{ Alcohol frequency; n (\%) } \\
\hline Does not/seldom drink & $21(77.8)$ & $8(34.8)$ & 0.01 \\
\hline 1-6 times/week & $5(18.5)$ & $9(39.1)$ & \\
\hline Everyday & $1(3.7)$ & $6(26.1)$ & \\
\hline \multicolumn{4}{|l|}{ Educational attainment; n (\%) } \\
\hline Up to High school & $17(63)$ & $0(0)$ & 0.00 \\
\hline Vocational school or Junior college & $7(25.9)$ & $14(60.9)$ & \\
\hline University or higher & $3(11.1)$ & $9(39.1)$ & \\
\hline \multicolumn{4}{|l|}{ Working status; n (\%) } \\
\hline Housework/Unemployed & $5(18.5)$ & $0(0)$ & 0.01 \\
\hline Full-time/ Part-time/ Self-employment & $17(63)$ & $23(100)$ & \\
\hline
\end{tabular}


Other

Past history; n (\%)

Cardiovascular disease

Diabetes mellitus

Liver disease

Malignant disease

Neuropsychiatric disorder

SD, standard deviation
$5(18.5) \quad 0(0)$

$11(40.7) \quad 7(30.4) \quad 0.56$

$5(18.5) \quad 3(13) \quad 0.71$

$6(22.2) \quad 5(21.7) \quad 1.00$

$3(11.1) \quad 0(0) \quad 0.24$

$7(25.9) \quad 1(4.3) \quad 0.06$ 
Table 2. Arsenic Species in Urine

\begin{tabular}{|c|c|c|c|}
\hline & $\begin{array}{l}\text { Exposed } \\
\qquad n=27\end{array}$ & $\begin{array}{l}\text { Unexposed } \\
\qquad n=23\end{array}$ & $\mathrm{p}$ value \\
\hline & mean (SD) & mean (SD) & \\
\hline iAs (ng /ml) & $1.46(0.69)$ & $1.8(1.1)$ & 0.14 \\
\hline MMAs (ng /ml) & $2.23(195.31)$ & $2.18(179.18)$ & 0.92 \\
\hline DMAs $\quad(\mathrm{ng} / \mathrm{ml})$ & $25.53(1763.5)$ & $29.13(2056.75)$ & 0.51 \\
\hline Sum of arsenic species $(\mathrm{ng} / \mathrm{ml})$ & $29.22(1932.56)$ & $33.16(2223.29)$ & 0.51 \\
\hline Ratio iAs/MAs & $0.95(51.45)$ & $1.08(44.54)$ & 0.33 \\
\hline Ratio MAs/DMAs & $0.1(9.3)$ & $0.08(3.73)$ & 0.18 \\
\hline
\end{tabular}

DMA; dimethylarsinic acid; MMA, monomethylarsonic acid; iAs, inorganic arsenic; SD, standard deviation 
Table 3. Physical status separated by exposure status.

\begin{tabular}{|c|c|c|c|c|c|}
\hline & \multirow{2}{*}{\multicolumn{2}{|c|}{$\begin{array}{l}\text { Exposed } \\
\qquad n=27\end{array}$}} & \multirow{2}{*}{\multicolumn{2}{|c|}{$\begin{array}{l}\text { Unexposed } \\
\qquad n=23\end{array}$}} & \multirow{3}{*}{$p$ value } \\
\hline & & & & & \\
\hline & $\mathrm{N}$ & mean $(\mathrm{SD})$ & $\mathrm{N}$ & mean $(\mathrm{SD})$ & \\
\hline \multicolumn{6}{|l|}{ Physical status } \\
\hline Height; cm & 27 & $155.2(10.6)$ & 23 & $161.7(8.8)$ & 0.02 \\
\hline Male & 14 & $161.8(7.1)$ & 10 & $168.6(7)$ & 0.03 \\
\hline Female & 13 & $148.1(9)$ & 13 & $156.3(5.9)$ & 0.01 \\
\hline Weight; kg & 27 & $57.8(14.2)$ & 23 & $60.4(12.1)$ & 0.49 \\
\hline Male & 14 & $62.1(16.2)$ & 10 & $69.7(7.3)$ & 0.18 \\
\hline Female & 13 & $53.1(10.2)$ & 13 & $53.2(10)$ & 0.98 \\
\hline BMI; kg/m² & 27 & $23.8(4.3)$ & 23 & $23.2(4)$ & 0.58 \\
\hline Male & 14 & $23.5(4.8)$ & 10 & $25(3.8)$ & 0.42 \\
\hline Female & 13 & $24.2(3.7)$ & 13 & $21.8(3.7)$ & 0.11 \\
\hline Systolic BP; mmHg & 27 & $125.7(15)$ & 23 & $122.4(21)$ & 0.51 \\
\hline Diastolic BP; mmHg & 27 & $74.6(11.2)$ & 23 & $70.9(12.3)$ & 0.27 \\
\hline
\end{tabular}

BMI; body mass index; BP, blood pressure; SD, standard deviation 
Table 4. Complete blood count and biochemical blood test separated by exposure status.

\begin{tabular}{|c|c|c|c|c|c|c|}
\hline & \multirow{3}{*}{ Reference values ${ }^{\mathrm{a}}$} & \multirow{2}{*}{\multicolumn{2}{|c|}{$\begin{array}{c}\text { Exposed } \\
\qquad n=27\end{array}$}} & \multirow{2}{*}{\multicolumn{2}{|c|}{$\begin{array}{c}\text { Unexposed } \\
\qquad n=23\end{array}$}} & \multirow{3}{*}{$p$ value } \\
\hline & & & & & & \\
\hline & & $\mathrm{N}$ & mean (SD) & $\mathrm{N}$ & mean $(\mathrm{SD})$ & \\
\hline \multicolumn{7}{|l|}{ Complete blood count } \\
\hline $\mathrm{WBC} ; / \mu \mathrm{l}$ & $3500-9000$ & 27 & $5538.9(1695.5)$ & 23 & $4864.8(1666.9)$ & 0.16 \\
\hline $\mathrm{RBC} ; 10^{4} / \mu \mathrm{l}$ & Male: 490-550; Female: 350-500 & 27 & $442.7(43.4)$ & 23 & $451.6(38.4)$ & 0.45 \\
\hline $\mathrm{Hb} ; \mathrm{g} / \mathrm{dl}$ & Male: $14-18 ;$ Female: $12-16$ & 27 & $13.9(1.3)$ & 23 & $14.4(1.1)$ & 0.11 \\
\hline $\mathrm{Ht} ; \%$ & Male: 40-50; Female: $35-45$ & 27 & $40.7(3.5)$ & 23 & $41.6(2.8)$ & 0.32 \\
\hline Platelet; $10^{4} / \mu 1$ & $15-35$ & 27 & $23.3(7.3)$ & 23 & $22.3(4.6)$ & 0.57 \\
\hline \multicolumn{7}{|l|}{ Biochemical blood test } \\
\hline Total bilirubin; mg/dl & $0.2-1.2$ & 23 & $0.7(0.3)$ & 23 & $0.8(0.5)$ & 0.29 \\
\hline GOT; U/L & $10-35$ & 27 & $22.7(10.1)$ & 23 & $22.1(4.7)$ & 0.80 \\
\hline GPT; U/L & $5-30$ & 27 & $26.5(12.7)$ & 23 & $22.3(9.3)$ & 0.20 \\
\hline$\gamma$-GTP; U/L & Male: $10-50$; Female: $10-30$ & 27 & $50.3(37)$ & 23 & $43.5(28.9)$ & 0.48 \\
\hline ALP; U/L & $100-350$ & 23 & $232.7(63.1)$ & 23 & $191(44)$ & 0.01 \\
\hline
\end{tabular}




$\begin{array}{lccccc}\text { LDH; U/L } & 120-220 & 25 & 193.5(36.6) & 23 & 191(24.9) \\ \text { ZTT; U } & 0-5 & 25 & 6.3(3.8) & 10 & 6.4(1.9) \\ \text { Total cholesterol; mg/dL } & 130-219 & 17 & 202.9(41) & 23 & 206.7(23.6) \\ \text { HDL cholesterol; mg/dL } & 40-100 & 27 & 65.4(17) & 23 & 63.6(18.2) \\ \text { LDL cholesterol; mg/dL } & 65-139 & 27 & 121.4(37.2) & 23 & 123.3(26) \\ \text { Triglyceride; mg/dL } & 30-149 & 27 & 111.1(75.8) & 23 & 108.1(46.1) \\ \text { Blood glucose; mg/dl } & 80-109 & 27 & 112.9(36.3) & 23 & 109.9(49.1) \\ \text { HbAlc_JDS; \% } & 4.3-5.8 & 27 & 5.6(1.1) & 23 & 5.4(0.8) \\ \text { BUN; mg/dL } & 8-20 & 19 & 15.9(5.4) & 0 & \text { Unmeasured } \\ \text { Cr; mg/dL } & \text { Male: } 0.5-1.0 ; \text { Female: } 0.4-0.8 & 27 & 0.7(0.2) & 23 & 0.83 \\ \text { e-GFR } & \text { Male: } 80-100 ; \text { Female: } 64-80 & 10 & 84.6(30.5) & 13 & 75.9(15) \\ \text { UA; mg/dL } & \text { Male: } 3.5-7.0 ; \text { Female: } 2.5-6.0 & 27 & 5.7(1.1) & 23 & 5.6(1.5)\end{array}$

ALP, alkaline phosphatase; BUN, blood urea nitrogen; Cr, creatinine; e-GFR, estimated Glomerular Filtration Rate; GOT, glutamate oxaloacetate transaminase; GPT, glutamate pyruvate transaminase; Hb, hemoglobin; HbA1c_JDS, hemoglobin A1c (Japan Diabetes Society value); Ht, hematocrit; LDH, lactase dehydrogenase; RBC, red blood cell; SD, standard deviation; UA, urinary acid; WBC, white blood cell; ZTT, thymol turbidity test; $\gamma$-GTP; $\gamma$-glutmyl transferase a Reference values are mainly obtained from Standard Textbook of Internal Medicine 8th edition written in Japanese. 
Table 5. Height and ALP value between the exposed and unexposed group, separated by sex.

\begin{tabular}{|c|c|c|c|c|c|}
\hline & \multicolumn{2}{|r|}{ Exposed } & \multicolumn{2}{|c|}{ Unexposed } & \multirow[t]{2}{*}{$p$ value } \\
\hline & $\mathrm{N}$ & mean (SD) & $\mathrm{N}$ & mean (SD) & \\
\hline \multicolumn{6}{|l|}{ Male $(n=24)$} \\
\hline Height; cm & 14 & $161.8(7.1)$ & 10 & $168.6(7)$ & 0.03 \\
\hline ALP; U/L & 13 & $215.4(70)$ & 10 & $190.4(45)$ & 0.34 \\
\hline \multicolumn{6}{|c|}{ Female $(n=26)$} \\
\hline Height; cm & 13 & $148.1(9)$ & 13 & $156.3(5.9)$ & 0.01 \\
\hline ALP; U/L & 13 & $255.2(46.9)$ & 10 & $191.4(45)$ & 0.00 \\
\hline
\end{tabular}

ALP, alkaline phosphatase; SD, standard deviation 